\title{
Integration of internal and external signals in intake control
}

\author{
BY D. A. BOOTH \\ Nutritional Psychology Research Group, School of Psychology, University of Birmingham, \\ Edgbaston Park, Birmingham B15 2 TT
}

A mechanism that controls dietary intake may facilitate or inhibit the individual's ingestion of one or more solid or liquid materials at a particular moment in time. Appetite for food and drink is the momentary net facilitation of the disposition to ingest. Some appetite-reducing (i.e. inhibitory) signals arise from transient effects of recent ingestion: the resulting disposition not to eat or drink is called satiety. That being the topic of the inaugural Symposium of the Nutrition and Behaviour Group of the Nutrition Society that the present review concludes, I shall concentrate on moderation of energy intake. Nevertheless, the facilitation of ingestion is considered when directly related to satiety signals.

\section{MEASUREMENT OF SATIETY SIGNALS}

Most recent papers on human satiety report simply the suppression of dietary intake following the consumption of food having known nutritional composition but unknown sensory and post-ingestional effects. This misconceives the control of energy intake as a fixed regulatory outcome of the disposition to eat and its post-ingestional suppression (Cabanac, 1971). Satiety mechanisms help to moderate intake but to an extent, rather, that depends entirely on how the individual integrates post-ingestional and other signals in interaction with the varieties of foods available at subsequent times (Booth, 1972a,b; Booth et al. 1976b). A food or a nutrient has no determinate satiety value: only the characteristics of each particular satiating mechanism can be measured, plus the time-course of stimulation of signals by specified eating habits (Booth, 1988a, 1989a).

An ingestion-induced suppression of appetite may slow the eating or drinking of an item, cause a switch to the ingestion of another item, bring that occasion of eating or drinking to an end, postpone or prevent the start of a later bout of ingestion or reduce its size or vigour. Thus, there are many possible indices of the strength of a satiety signal. Whichever ingestion-specific inhibitory effect is used as index, its relative sensitivity to a particular source of satiety is the only sound measure of that signal's satiating power. For example, if we use meal sizes or intervals between meals as indices, we need to know the proportion of their normal variation that is under the control of the particular signal; it is indeterminate whether reducing the size of a meal by $25 \%$ is a strong or weak satiety effect unless we know the range of sizes produced by usual combinations of satiety signals (Smith \& Gibbs, 1979; Booth, 1985).

Traditional psychophysical assessment of sensations labelled satiating has been applied to distension of the stomach (Coddington \& Bruch, 1970), but signal sensitivity has been analysed only for hunger pangs and gastric motility, and then merely qualitatively (Griggs \& Stunkard, 1964). Gastric distension without other effects of ingestion, however, is an unrealistic fragment of the normal satiating pattern. Yet assessment of an internal signal in the normal context confounds it with how much is left on the plate and 
by memory of the size and timing of the last meal; hence, simply relating the index to the internal state does not measure that signal (Booth, 1989b).

Concurrent signals are often assumed to add or subtract. However, internal and external signals have been shown to interact non-linearly in their influence on ingestion: the complex of discrete sources of satiation acts as a single unity when all the signals are present (Booth, 1972b, 1985).

Such integration of several signals into appetite has been measured in individual people (Conner et al. 1988; Booth \& Conner, 1991; Booth et al. 1991) by multidimensional elaboration of the difference-threshold version of signal detection theory (Ashby \& Perrin, 1988; Ennis et al. 1988). Combinations of several sorts of external signal have been measured, including tastes, smells, textures and information about energy content of drinks or foods (Booth \& Blair, 1989). For example, taste mixtures are integrated into preferred and satisfying concepts such as citrus or savoury, multiple mechanical stimuli into the feel of creaminess, and taste, texture and aroma into the most acceptable formulation of chicken soup. Feeling full is also an integral of several sorts of stimulus. It will, therefore, be important to extend these quantitative methods to the qualitatively demonstrated integrations of internal signals with external signals reviewed.

\section{SIGNAL-ADAPTING EFFECTS OF INTERNAL SATIETY SIGNALS}

Research on internal sources of satiation of appetite for food was reviewed earlier in the present Symposium (Forbes, 1992; Rayner, 1992; Read, 1992). These signals include mechanical and chemical stimulation of the wall of the gastrointestinal tract and of receptors or cellular metabolism in the liver and perhaps the brain. At levels generated by digestion of a normal diet, such signals can be shown to inhibit food intake under appropriate test conditions.

In addition, internal satiety signals can adapt the effects of other appetite or satiety signals, alone or in combination. When they adapt combinations of signals, the satiety signals are inducing integration among those signals. This integration may be among external signals or between an external and an internal signal. Since integration is the topic of the present review, these adapting actions of satiety signals discussed in the previous reviews (Forbes, 1992; Rayner, 1992; Read, 1992) are now illustrated.

Learning from metabolic satiety. First, there are the signal-adapting effects of metabolic satiety. The supply of substrates to hepatic oxidation has been proposed to be the fundamental internal signal of energetic satiety-appetite in omnivores (Booth, 1972a,d; Booth et al. 1972, 1976b). This is not merely because it may be the final, longest-lasting and most generically energetic of the sequence of post-ingestional satiety signals. The proposal is based at least as crucially on evidence that the supply of energy substrates to the liver also adapts the effects of other internal and external signals controlling intake (Booth et al. 1972; Booth \& Davis, 1973; Tordoff \& Friedman, 1986; Sclafani \& Nissenbaum, 1988) and indeed induces the integration of gastrointestinal and dietary signals (Booth \& Davis, 1973; Booth \& Toase, 1983; Deutsch, 1983; Gibson \& Booth, 1989).

That is, metabolic satiety induces new effects of food flavours and textures, gastric distension and bells or times read off the clock. Indeed, these acquired effects achieve these signals' normal moment-to-moment control of foraging and ingestive choices and, hence, cumulatively of dietary intakes. 
Such induction or adaptation of behavioural control is known as learning. The training effects of metabolic satiety demonstrated thus far meet the criteria for basic associative learning, i.e. discriminative reinforcement of ingestive acts or associative conditioning of ingestive reactions to the distension, flavour and mealtime signals (Booth \& Davis, 1973; Booth, 1980 b 1985). In so far as these learned responses are specific to dietary signals, they can be described as internal-state-dependent conditioned preferences for the sensory cues which have been associated with the metabolic consequences.

All learning processes are mediated by changes in synaptic efficiencies in brain networks (Booth, 1967). The basic associations go on unconsciously but also we can be aware of similar processes at a conceptual level (Booth, 1987). We may, for example, become more attracted to an item on the menu in certain circumstances because we recall past satisfaction from eating that recipe in such circumstances.

Duodenally conditioned aversion and satiety. The second sort of satiety signal that conditions other signals is probably duodenal (Booth \& Davis, 1973). Concentrated maltodextrin is specifically relevant to the present Symposium in that it can condition inhibition to integral internal-external signals (Gibson \& Booth, 1987). Some of the starch is dumped into the duodenum before its digestion delivers enough maltose and glucose to the duodenal wall to slow gastric emptying. Further digestion of this bolus may then free maltose faster than it can be hydrolysed at the wall and absorbed, so creating some transient osmotic distension that is a powerful satiety signal (Booth, 1981). This transient bloating effect conditions an aversion to the sensory characteristics in combination with the mild fullness present at the end of the meal (Booth \& Davis, 1973; Booth et al. 1982), i.e. conditions a food-specific satiation.

This maltodextrin-conditioned relative aversion is integrated with internal signals arising specifically towards the end of a meal (Booth, 1972c; Booth \& Toase, 1983). It must not be confused with the relative aversion present from near the start of a meal that is conditioned by hypertonic sugar loads (Le Magnen, 1959; Davis \& Smith, 1990).

\section{LEARNED INTERNAL-EXTERNAL INTERACTION}

Several external and internal satiety signals are likely to be operative at a given moment during or after meals. Hence, the signals usually have to be combined into any momentary decision whether or not to reject a food item. For species consuming a wide variety of foods, and also having to deal with (at least in the human case) cultural as well as biological effects of eating and drinking, this integration of internal and external signals must rely on memory of past experiences. That is, we should expect normal control of intake to be entirely learned in omnivorous species. Innate interactions between, say, taste and gastric distension or blood glucose level could have no function, except perhaps at extremes.

Learned integration implies mutual specificity of external and internal signals. The example given previously was the rejection of a particular food during a particular gastrointestinal state that is acquired after association of that conjunction of signals from diet and digestive tract with mildly aversive oversatiation (Booth, 1972b, 1980a; Gibson \& Booth, 1987). The converse (learned distension-dependent and food-specific desatiation) has been extensively investigated in rats (Booth, 1972b, 1980a; Booth \& Davis, 1973; Gibson \& Booth, 1989), monkeys (Booth, 1982) and people (Booth et al. 1976a, 1982; Booth \& Toase, 1983), as also has learned protein-specific desatiation-hunger (Gibson \& Booth, 1986; Baker et al. 1987). 
The same learning of internal and external integration in the control of food intake has been observed in 2- to 4-year-old children (Birch \& Deysher, 1985). Visceral consequences of eating seem to be important in acquisition of this control: learning is stronger when the children's attention is focused on their insides by, for example, demonstrating the stomach of a transparent doll filling with items put in its mouth (Birch et al. 1987). Since Birch et al. (1987) find adults to be poorer at satiation conditioning than children, they suggest that children are less distracted by conventions and would be better left to control their own intake than nagged into eating up (or down) by adults.

A possibly related finding is that dieters who have been more successful at reducing weight towards their target learn appetite and desatiation better than less successful ones, and even perhaps than non-dieters (Booth \& Toase, 1983). Part of their success may also come from attending to the sensations produced by eating, permitting autosuggestive processes to amplify any unconsciously conditioned reduction of interest in desserts and snacks (Booth, 1976, 1980b).

\section{EXTERNAL SATIETY SIGNALS}

Appetite can be inhibited by a great variety of external factors, such as risk of predation for small mammals or risk of failure for human performers at examinations, Symposium talks, etc. However, satiety is ingestion-generated inhibition and so external satiety signals are by definition limited to interactions with the diet before it enters the body. Sensory qualities of foods are often integrated with eating situations to generate satiety, such as in the case of how much food is left on the plate or of the appropriateness of stopping eating to the menu or to the time of day.

Food-specific boredom. Eating a food may inhibit the desire to eat that particular food afterwards for at least some minutes (Rolls et al. 1982). Longer-term boredom may develop to a menu that is repeated too often. This aspect of satiation appears to be a form of habituation (Booth, 1976; Clifton et al. 1987; Swithers-Mulvey et al. 1991). Unlike conditioned satiation, however, this form of food-specific satiety is not integrated with internal signals (Rolls et al. 1982; Swithers-Mulvey et al. 1991).

Externally triggered appetite and satiety. We were so impressed by the strength of the facilitation conditioned to dietary signals by metabolic satiety that we proposed energetic conditioning to be the foundation of all appetite for food (Booth et al. 1972), not just generating enthusiasm in eating and determining choice among foods but also instigating meals and accounting for cravings for foods, emotional overeating and the compulsion to binge (Booth, 1980b, 1988b). Conditioned initiation of meals by environmental signals has indeed been confirmed in rats (Weingarten, 1984).

These conditioned instigators of eating may act by countering residual internal satiety signals, such as those that arise in people from metabolism of dietary protein and perhaps fat (Booth et al. 1970; French et al. 1992). The evidence in rats does not distinguish such subtractive interaction from integration between the environmental and internal signals, because the conditioned initiation has been tested in freely feeding animals which have a wide variety of internal states (Booth, 1972c).

Nevertheless, there is some indirect evidence for integration of the dinner bell or time of day with dietary signals and even with internal signals as well. This could be the unconscious learning mechanism underlying concepts of the appropriateness of foods to occasions (Schutz, 1989). For example, some foods are considered to be suitable for 
meals at particular times of day, e.g. a bowl of cereal at breakfast rather than in the late afternoon; young children begin to learn these adult conventions (Birch et al. 1984). This has been interpreted as a conceptual structure built on conditioning of appetite (Booth, $1987,1988 b$ ), but some recent evidence weighs against the idea that appropriateness is expressed during ingestion; rather, the suitability of a food to breakfast-time as opposed to lunchtime is evident in post-prandial satisfaction (Kramer et al. 1992). Hence, in the USA the contrast between breakfast and lunch may be built on the conditioning of satiety.

\section{INTERNAL SIGNALS IN RATED SATIETY}

In human subjects, the disposition to ingest can be expressed verbally in some form of a wish to eat or drink or not, e.g. 'I'm hungry' or 'No, I won't have any more of that now, thank you'. Investigators frequently ask participants to grade the strength of the expressed disposition (rate appetite) in the hope that the score will measure (scale) the intensity of this motivation in that person at that moment. Scales of hunger, thirst and their suppression are, however, established only by specific calibration of the verbal behaviour (as for any scientific measurement), e.g. on the amount actually eaten or drunk when the wish is granted, or by the indirect procedures of consensual multivariate decorrelation that were developed by questionnaire psychologists, called psychometric scaling.

People often attribute appetite or loss of appetite to a bodily sensation such as dryness of the mouth, an epigastric pang, upper abdominal fullness or less localized nausea. Verbally different sensation rating scores also tell us nothing about influences on intake until shown to be specific measures of different sorts of physiological process (Welch et al. 1988) or at least to be uncorrelated with each other and with confounding factors such as memory of the time, composition and size of the last meal (Booth, 1989b). Ratings of the strength of the fullness sensation may often refer unconsciously to such memories rather than being sensitive to current tension in the wall of the stomach (or duodenum, or indeed to chemoreception or even hepatic energy metabolism). The experience of fullness may be constructed from occasional sensing of gastric or duodenal distension but this may be hard to discriminate from other inhibitory post-ingestional effects and readily generalized to the concept of filling a bag in the body and conventional language for refusing offers of additional food (Booth, 1980b, 1987).

Thus, we have hardly begun to map bodily sensations onto signals actually controlling intake. It is a much more difficult task than usually acknowledged, because verbal expression of subjective experience is built up by interpreting present patterns of signals from the external and internal environments in the light of past series of patterns.

\section{CONCLUSION}

Most studies of satiety fail to allow for the sensed characteristics of foods and the contexts of the eating occasions. Yet these are as much part of the ingestion-induced inhibition of appetite as is the physiological state. Clearly, until both external and internal sources of satiety are routinely measured and controlled, there will continue to be a dearth of information on the integration of signals controlling the food choices resulting in nutrient intake, arguably one of the main fundamental scientific problems for behavioural nutrition. 


\section{REFERENCES}

Ashby, F. G.\& Perrin, N. (1988). Towards a unified theory of similarity and recognition. Psychological Review 95, 124-150.

Baker, B. J., Booth, D. A., Duggan, J. P. \& Gibson, E. L. (1987). Protein appetite demonstrated: learned specificity of protein-cue preference to protein need in adult rats. Nutrition Research 7, 481-487.

Birch, L. L., Billman, J. \& Richards, S. S. (1984). Time of day influences food acceptability. Appetite 5, $109-116$.

Birch, L. L. \& Deysher, M. (1985). Conditioned and unconditioned caloric compensation: Evidence for self-regulation of food intake by young children. Learning and Motivation 16, 341-355.

Birch, L. L., McPhee, L., Shoba, B. C., Steinberg, L. \& Krehbiel, R. (1987). 'Clean up your plate': effects of child feeding practices on the conditioning of meal size. Learning and Motivation 18, 301-317.

Booth, D. A. (1967). Vertebrate brain ribonucleic acids and memory retention. Psychological Bulletin 68, 149-177.

Booth, D. A. (1972a). Satiety and behavioral caloric compensation following intragastric glucose loads in the rat. Journal of Comparative and Physiological Psychology 78, 412-432.

Booth, D. A. (1972b). Conditioned satiety in the rat. Journal of Comparative and Physiological Psychology $\mathbf{8 1}$, $457-471$.

Booth, D. A. (1972c). T'aste reactivity in satiated, ready to eat and starved rats. Physiology and Behavior $\mathbf{8}$, 901-908.

Booth, D. A. (1972d). Postabsorptively induced suppression of appetite and the energostatic control of feeding. Physiology and Behavior 9, 199-202.

Booth, D. A. (1976). Approaches to feeding control. In Appetite and Food Intake, pp. 417-478 [T. Silverstone, editor]. Berlin: Abakon/Dahlem Konferenzen.

Booth, D. A. (1980a). Conditioned reactions in motivation. In Analysis of Motivational Processes, pp. 77-102 [F. M. Toates and T. R. Halliday, editors]. London: Academic Press.

Booth, D. A. (1980b). Acquired behavior controlling energy intake and output. In Obesity, pp. 101-143 [A. J. Stunkard, editor]. Philadelphia: W. B. Saunders.

Booth, D. A. (1981). The physiology of appetite. British Medical Bulletin 37, 135-140.

Booth, D. A. (1982). Normal control of omnivore intakes by taste and smell. In Determination of Behaviour by Chemical Stimuli, pp. 233-243 [J. E. Steiner and J. R. Ganchrow, editors]. London: IRL Press.

Booth, D. A. (1985). Food-conditioned eating preferences and aversions with interoceptive elements: learned appetites and satieties. Annals of the New York Academy of Sciences 443, 22-37.

Booth, D. A. (1987). Cognitive experimental psychology of appetite. In Eating Habits, pp. 175-209 [R. A. Boakes, M. J. Burton and D. A. Popplewell, editors]. Chichester: Wiley.

Booth, D. A. (1988a). Mechanisms from models - actual effects from real life: the zero-calorie drink-break option. Appetite 11, Suppl., 194-102.

Booth, D. A. (1988b). Culturally corralled into food abuse: the eating disorders as physiologically reinforced excessive appetites. In The Psychobiology of Bulimia Nervosa, pp. 18-32 [K. M. Pirke, W. Vandereycken and D. Ploog, editors]. Heidelberg: Springer-Verlag.

Booth, D. A. (1989a). The effect of dietary starches and sugars on satiety and on mental state and performance. In Dietary Starches and Sugars in Man: A Comparison, pp. 225-249 [J. Dobbing, editor]. London: Springer-Verlag.

Booth, D. A. (1989b). Summary: Concluding Session. Annals of the New York Academy of Sciences 575, $466-471$.

Booth, D. A. \& Blair, A. J. (1989). Objective factors in the appeal of a brand during use by the individual consumer. In Food Acceptability, pp. 329-346 [D. M. H. Thomson, editor]. London: Elsevier Applied Science.

Booth, D. A., Chase, A. \& Campbell, A. T. (1970). Relative effectiveness of protein in the late stages of appetite suppression in man. Physiology and Behavior 5, 1299-1302.

Booth, D. A. \& Conner, M. T. (1991). Characterisation and measurement of influences on food acceptability by analysis of choice differences: theory and practice. Food Quality \& Preference 2, 75-85.

Booth, D. A. \& Davis, J, D. (1973). Gastrointestinal factors in the acquisition of oral sensory control of satiation. Physiology and Behavior 11, 23-29. 
Booth, D. A., Freeman, R. P. J. \& Lähteenmäki, L. (1991). Likings for complex foods and meals. Appetite 17, 156.

Booth, D. A., Lee, M. \& McAleavey, C. (1976a). Acquired sensory control of satiation in man. British Journal of Psychology 67, 137-147.

Booth, D. A., Lovett, D. \& McSherry, G. M. (1972). Postingestive modulation of the sweetness preference gradient in the rat. Journal of Comparative and Physiological Psychology 78, 485-512.

Booth, D. A., Mather, P. \& Fuller, J. (1982). Starch content of ordinary foods associatively conditions human appetite and satiation, indexed by intake and eating pleasantness of starch-paired flavours. Appetite 3, 163-184.

Booth, D. A. \& Toase, A. M. (1983). Conditioning of hunger/satiety signals as well as flavour cues in dieters. Appetite 4, 235-236.

Booth, D. A., Toates, F. M. \& Platt, S. V. (1976b). Control system for hunger and its implications in animals and man. In Hunger, pp. 127-142 [D. Novin, W. Wyrwicka and G. A. Bray, editors]. New York: Raven Press.

Cabanac, M. (1971). Physiological role of pleasure. Science 173, 1103-1107.

Clifton, P. G., Burton, M. J. \& Sharp, C. (1987). Rapid loss of stimulus-specific satiety after consumption of a second food. Appetite 9, 149-156.

Coddington, R. C. \& Bruch, H. (1970). Gastric perceptivity in normal, obese and schizophrenic patients. Psychosomatics 11, 571-579.

Conner, M. T., Haddon, A. V., Pickering, E. S. \& Booth, D. A. (1988). Sweet tooth demonstrated: individual differences in preference for both sweet foods and foods highly sweetened. Journal of Applied Psychology 73, 275-280.

Davis, J. D. \& Smith, G. P. (1990). Learning to sham feed. American Journal of Physiology 259, R1228-R1235.

Deutsch, J. A. (1983). Dietary control and the stomach. Progress in Neurobiology 20, 313-332.

Ennis, D. M., Palen, J. J. \& Mullen, K. (1988). A multidimensional stochastic theory of similarity. Journal of Mathematical Psychology 32, 449-465.

Forbes, J. M. (1992). Metabolic aspects of satiety. Proceedings of the Nutrition Society 51, 13-19.

French, J., Wainwright, C. J., Booth, D. A. \& Hamilton, J. (1992). Effect of meat species and particle size on postprandial satiety. Proceedings of the Nutrition Society 51, this issue.

Gibson, E. L. \& Booth, D. A. (1986). Acquired protein appetite in rats: dependence on a protein-specific need state. Experientia 42, 1003-1004.

Gibson, E. L. \& Booth, D. A. (1987). Paraventricular noradrenaline injection modulates learned integration of visceral satiety signals and dietary stimuli. Neuroscience Letters Suppl. 29, S97.

Gibson, E. L. \& Booth, D. A. (1989). Dependence of carbohydrate-conditioned flavor preference on internal state in rats. Learning and Motivation 20, 36-47.

Griggs, R. C. \& Stunkard, A. J. (1964). The interpretation of gastric motility. II. Sensitivity and bias in the perception of gastric motility. Archives of General Psychiatry 11, 82-89.

Kramer, F. M., Rock, K. \& Engell, D. (1992). Effects of appropriateness to time of day and on food intake and hedonic ratings. Appetite 18, 1-13.

Le Magnen, J. (1959). Effets des administrations postprandiales de glucose sur l'établissement des appétits. Comptes Rendues des Seances de la Societe de Biologie, Paris 153, 212-215.

Rayner, D. V. (1992). Gastrointestinal satiety in animals other than man. Proceedings of the Nutrition Society $51,1-6$.

Read, N. W. (1992). Control of hunger and satiety by stimulation of gastrointestinal receptors in man. Proceedings of the Nutrition Society 51, 7-11.

Rolls, B. J., Rolls, E. T. \& Rowe, E. A. (1982). The influence of variety on human food selection and intake. In Psychobiology of Human Food Selection, pp. 101-122 [L. M. Barker, editor]. Westport, CT: AVI.

Schutz, H. G. (1989). Appropriateness as a measure of contextual acceptance. In Food Acceptability, [D. M. H. Thomson, editor]. London: Elsevier Applied Science.

Sclafani, A. \& Nissenbaum, J. W. (1988), Robust conditioned flavor preference produced by intragastric starch infusion in the rat. American Journal of Physiology 255, R672-R675.

Smith, G. P. \& Gibbs, J. (1979). Postprandial satiety. Progress in Psychobiology and Physiological Psychology 10, 179-242.

Swithers-Mulvey, S. E., Miller, G. L. \& Hall, W. G. (1991). Habituation of oromotor responding to oral infusion in rat pups. Appetite 17, 55-67. 
Tordoff, M. G. \& Friedman, M. I. (1986). Hepatic-portal glucose infusions decrease food intake and increase food preference. American Journal of Physiology 251, R192-R195.

Weingarten, H. P. (1984). Meal initiation controlled by learned cues: basic behavioral properties. Appetite 5, 147-158.

Welch, I. M., Cunningham, K. M. \& Read, N. W. (1988). Regulation of gastric emptying by ileal nutrients in man. Gastroenterology 94, 401-404. 